clearly described and contrasted. Professor Berry then describes the many sense organs of man, and also the microscopic structure of that part of the brain which subserves intellect. He illustrates the nature of nervous reflex action by such familiar annoyances as toothache and blushing, and by a contemplation of the neuronic machinery concerned in the vocabulary of Shakespeare. There are two chapters on mental deficiency, in which the writer tilts at the antiquated McNaughton rules, and toys, perhaps too seriously, with euthanasia, without any regard to the evil social reverberations which might follow its practice.

An extraordinary amount of information is conveyed in these 158 small pages. Although the argument is greatly condensed, the reader must not expect to find it correspondingly simplified. The reading demands much thought. Professor Berry scores, and scores heavily, over other popular writers on the brain with his diagrams and photographs. These are many, all excellent and some exquisite. So apt and informative are these illustrations that the book can be re-read from them alone. They are printed with that masterly clarity which we expect from the Oxford University Press.

T. A. Munro.

Guiding Human Misfits. By Alexandra Adler. Faber \& Faber. 5s.

A simple, well-written and extremely wellproduced exposition of some of the basic facts in the modern handling of the mentally unfit by the daughter of the late Professor Adler, which calls for more notice than it is usual to accord to the plethora of such short popular expositions.

Miss Adler emphasizes once more her father's individual approach, and the necessity of treating each case as a complex of elements best understood from a study of the circumstances and history of the individual person. This in fact is Adler's most significant contribution to the technique of the modern child guidance clinic. Those who were privileged to hear Professor Adler on the occasion of his last visit to London will remember that he considered that the three important issues in the life of the individual were his adjustment to society, to his work, and to the problem of his love relationships. Miss Adler simplifies these issues in dealing with the problems of childhood and adolescence, and with the psychology of the neurotic and the criminal.

In a book of a hundred odd pages, however, the field is too vast to justify a popular approach even by Miss Adler. There is in addition a highly misleading and fanciful chapter on dreams, which belies all Professor Adler's insistence on the individual approach. It reads instead like the old dream books of a more credulous age, and is not really any more scientific.

The book abounds in easy generalizations which do not escape notice, though they might not be expected in a book from such a source. There must be comfort to the dictators, for instance, in the following: "The spirit of the people who have contributed to social development will never die. But what becomes of those people who have been a hindrance ? We find no trace of them in history; they have left nothing. Only the useful accomplishments are included and those who work against progressive developments disappear." Not thus can psychological writers contribute to the millenium.

R.T.

New Ways in Psychoanalysis. By Karen Horney. Kegan Paul. International Library of Psychoanalysis. 12s. 6d.

The author has been brought up in the Freudian school, but has certainly not succumbed to the paralysing influence of orthodoxy as some disciples have done, especially since the earlier defections of such pioneers as Jung, Adler and Steckel. In her heretical conclusions she is probably nearest to Steckel, but she is by no means a disciple of his. In this book she takes all the main tenets of the Freudian doctrine except the fundamental ones of conflict and repression, and subjects them to stringent criticism.

Briefly, while Freud holds that mental illness is determined almost exclusively by erotic stresses in very early childhood, Dr. Horney lays stress on the character drives in the present situation. Freud holds that if these infantile stresses are laid bare, the emotional " working out " involved in the unmasking of the repressed material liberates the patient so that he can adjust to present circumstances without more ado, and if he fails in this, the reason is that all the repressions have not been resolved. Hence the very prolonged analysis of Freudian practice. In this book it is held, on the contrary, that what is required is that the patient must be shown how his character drives are shaping his behaviour and producing his neurotic symptoms, and that he must be taught to redirect his will so as to adapt to reality with better advantage.

The author points out that the resistance of the patient depends on his essential feeling of insecurity and his unwillingness that the picture of himself as a perfect personality in order to protect himself from that very insecurity should be assailed. 
There is no doubt that this is a highly interesting and stimulating book and that it does reflect the general attitude of many modern psychotherapists, especially in this country, but it must not be thought that this is an easy simplification of the difficult Freudian doctrine which can be assimilated by the uninitiated, and it is very doubtful if anyone who is not well acquainted with analytic theory and practice will get much value from it:

Towards Mental Health in School. By C. Roger Myers, M.A., Ph.D. University of Toronto Press. pp. 151. 7s.

This is an excellent little book written for teachers. It is brief, clear and, if in places a little too dogmatic and unduly optimistic, it is none the worse for that.

As the author says, education is largely a waste of effort if the recipient is not in good health, but while teachers have done much in the past to promote physical health, they pay scant attention to the mental health of these pupils, which is even more important.

If we are to keep mentally healthy we must face facts, and two chapters are devoted to the exposition of the true facts, as to the frequency and nature of mental illness and to exploding false notions commonly held by the lay public regarding them.

The next two chapters are devoted to mental defect, which the author very rightly describes as a minor problem compared with mental illness. This is a point that might well be taken in this country, where intellectual impairment is still erroneously regarded as far more important than emotional impairment. The causes of mental deficiency are discussed; and if the author lays less stress on heredity than some would consider justifiable, he rightly points out that while mental defectives cannot be improved in their mental capacity, they can all be raised to the limits of their capacity by careful and suitable instruction. Many teachers would do well to take to heart the remark, " It would be as senseless to whip a weak child for failing to lift a heavy weight as to punish a mentally defective child for failing to add or spell correctly."

The mental diseases are next discussed with remarkable accuracy, considering the simple language used. Exception might be taken to the implication that the functional psychoses are nothing but perpetuations of faulty habits of adjustment to environment acquired in childhood, but nothing but good can come of the exhortation to teachers to do their best to help children to free themselves from, or better still to avoid faulty attitudes towards life. Amongst the methods, perhaps one of the most important is the avoidance of too much competition, especially speed tests, for in these the same children will almost always lead and the same group will always fail, and whether the overweaning conceit induced in the first group or the inferiority of the last is the greater evil is a moot point.

In the second part of the book, which deals more specifically with the problem of the child in school, these faults are excellently described and the proper attitude of the teacher is outlined. The latter is specially warned that the naughty child is much more likely to be emotionally healthy than the over-good child, and a very true adage is quoted: "There are three main principles to employ in the treatment of the timid child", or, indeed, of any child. "The first is tact, the second is tact, and the third is tact." Finally, there is a valuable chapter on the preservation of the teacher's own mental health, for, as has been statistically proved, it is found that there is a greater proportion of emotionally unstable children in the classes of teachers who are themselves not well adjusted in their emotions, than in those with a sane and calm outlook on life.

Altogether an admirable little book which all might read with profit.

\section{THE NATIONAL COUNCIL FOR MENTAL HYGIENE}

List of Recent Publications

NERVOUS CHILDREN AND HOW TO RECOGNIZE THEM

PSYCHOLOGICAL TRAINING IN THE NURSERY-THREE TALKS FOR PARENTS

SEX TEACHING FOR CHILDREN-A GUIDE FOR PARENTS, SCHOOL TEACHERS, ETC.

SUICIDE-WHAT MEDICAL PSYCHOLOGY SAYS ABOUT IT

Price 3d. each, postage extra.

To be obtained from

The Secretary, N.C.M.H., 76-77 Chandos House, Palmer Street, London, S.W.1 